\title{
The Effect of Permanent Employment on Absenteeism: Evidence from Labor Reforms in Spain.
}

\author{
Inmaculada García*, Colin P. Green** and María Navarro** \\ * Department of Economic Analysis, University of Zaragoza \\ ** Department of Economics, Lancaster University
}

\begin{abstract}
Restrictive employment protection legislation has been highlighted as one of the key reasons for lower labour productivity in Europe compared to the US. A variety of channels have been suggested, including a focus on the direct effect of employment protection on worker effort. Evidence now exists that demonstrates robust, but small, effects of employment protection on effort. These appear too small to generate marked cross-country differences in labour productivity. This paper revisits this issue using representative data of private sector workers in Spain. A range of legislative changes aimed at reducing the incidence of temporary employment are used to estimate the effect of permanent employment on one aspect of effort, absenteeism. A substantial effect of permanent contracts on absenteeism is found. These results suggest that cross-country differences in employment protection have the potential, through the effect on worker effort, to have a substantial impact on labour productivity.
\end{abstract}

JEL codes: J22, J38

Keywords: Absenteeism, Temporary Employment, Employment Protection

Acknowledgments: The authors would like to thank Juan Ramon García, John Heywood, Jean-Francois Maystadt and seminar participants at the 2012 Work, Pensions and Employment Group Conference, the 2012 EALE meetings, the 2013 Beyond Wages Conference at the British Academy, the 2015 joint meetings of EALE and SOLE and the Melbourne Institute for helpful comments. For their suggestions which improved the paper, we would like to thank the editor Adrianna Kugler and two referees. María Navarro gratefully acknowledges financial support from the LUMS Pump-priming Grant ECA6364. 


\section{Introduction}

Differences in labor productivity between Europe and the US are an issue of longstanding interest (Prescott, 2004; Timmer and van Ark, 2005 and van Ark, O’Mahony, and Timmer, 2008). A range of explanations have been posited to explain these differences. For instance, it has been suggested that the 'knowledge economy' emerged much more slowly in Europe when compared to the US (Aghion, Blundell, Griffith, Howitt and Prantl 2004; van Ark et al. 2008). Another explanation, and a highly contentious one, is that markedly more strict employment protection legislation (EPL) in Europe leads to lower labour productivity (Bassanini, Nunziata and Venn, 2009; Dolado and Stucchi, 2008; Capellari, Dell'Aringa and Leonardi, 2012).

EPL has the potential to affect productivity through its influence on labor market transitions and unemployment: this has been the source of a large and contentious literature (Lazear, 1990; Addison, Teixera and Grosso, 2000; Blanchard and Portugal, 2001; Acemoglu and Angrist, 2001 and Kugler and Pica, 2008). Along with these effects on labour market transitions EPL could also influence worker productivity more directly through its influence on worker effort decisions (Dolado and Stucchi, 2008 and Dolado, Ortigueira and Stucchi, 2011). Recently, a literature has developed that seeks to estimate this effect, focusing primarily on absenteeism (Riphahn and Thalmaier, 2001; Ichino and Riphahn, 2004 and 2005; Engellandt and Riphahn, 2005; Olsson, 2009, Scoppa, 2010a; Bradley, Green and Leeves, 2014). This literature can be summarized as showing robust and statistically significant effects of employment protection on absenteeism; more employment protection increases absenteeism. While these papers typically compare worker behaviour across large variations in employment protection, it must be recognized that the economic magnitude of these estimated effects are quite small. For instance, Ichino and Riphahn (2005) show that Italian bank workers who pass a 12 week probation period increase absence by 0.04 of a day per week, while Bradley et al. (2014) show that public sector workers who move from temporary to permanent contracts increase absence by 0.017 of a day per week. These effects seem too small to lead to large differences in labour productivity. Other studies find larger effects in specific settings related to small firms. Olsson (2009) finds a decrease in sickness absence of $13 \%$ among firms of less than 10 workers in Sweden who experienced a reduction in employment protection strength, and Scoppa (2010a) examine the effect of an increase in dismissal costs in small Italian firms and find an increase in sickness absence of $18 \%$. 
Finally, previous evidence for Spain demonstrates a small effect of permanent contracts on the incidence of absenteeism (Jimeno and Toharia, 1996).

In this paper we revisit this issue and provide new evidence on the effect of permanent contracts on private sector worker absence across an entire labor market. Using variation in the probability of assignment to permanent contracts that result from a series of legislative changes in Spain, we demonstrate larger effects of contract type on worker absence than previous estimates. We argue that these are of a magnitude large enough to generate economically meaningful differences in worker productivity.

In the European context the key variation in employment protection relates to differences between temporary contracts and permanent contracts. Temporary contracted workers are relatively easy to fire or face non-renewal of contract while the dismissal of permanent workers is, typically, extremely difficult. In the case where dismissal of permanent contract workers does occur this may still impose large costs on the employer. Spain is a particularly interesting case as it is known for both very stringent employment protection of permanent employees and at the same time has the highest incidence of temporary employment contracts in the EU. More than $30 \%$ of the Spanish workforce over the 19902007 period was employed on a fixed-term contract at any given point in time (Bentolila, Dolado and Jimeno, 2008), and these workers have very little employment protection. Previous evidence suggests that there is limited mobility between temporary and permanent contracts, for instance temporary contract worker chance of moving into permanent employment appears no higher than that of unemployed individuals (Güell and Petrongolo, 2007).

The temptation in this context is to compare temporary and permanent workers to provide a measure of the effect of contract type on effort. However, the identification of the effect of permanent employment on workers' effort is complicated by a number of issues related to the non-random selection of workers into employment contracts. First, contract type is not randomly distributed across the labour market and temporary contracts are, for instance, concentrated amongst the young, women, immigrants and the less skilled (Kahn, 2007). Moreover, temporary jobs are characterized by features that may make them on average less desirable, such as lower levels of work-related training (Arulampalam and Booth, 1998; Draca and Green, 2004), lower wages (Booth, Francesconi and Frank, 2002), poorer working conditions, and an increased risk of work-related accidents (Guadalupe, 
2003). A further complication is that these contracts could be used for specific reasons that may condition effort choices. For instance, they may be used by employers as a buffer against cyclical fluctuations and/or for screening purposes (Booth et al. 2002; Green and Leeves, 2004). In the latter case, under imperfect information regarding their productivity, this may lead temporary workers to increase their effort so as to augment their probability of being retained by the firm.

Together this suggests a variety of observed and unobserved factors that influence both the probability of being hired on a permanent contract and effort choices by workers. This suggests an endogeneity problem leading to biased and inconsistent estimates of the causal effect of contract type on absenteeism. This paper investigates the effect of permanent contracts on workers' effort by exploiting three employment protection reforms between 1997 and 2002 in Spain that incentivized private sector firms to offer permanent contracts to certain groups of workers while leaving others unaffected. These reforms are used as a source of exogenous variation in permanent employment, which is then used to estimate contract effects on absenteeism. Previous research has already shown that these types of labor reforms affect the likelihood of being employed on a temporary contract. Kahn (2010) finds an effect of employment protection reforms on the incidence of temporary jobs for the countries of the EU-15 from 1996 to 2001. Dolado et al. (2011) use the 1994, 1997 and 2002 reforms in Spain to identify the exogenous variation in the share of temporary workers within firms so as to evaluate the impact of the extended use of temporary contracts on the productivity of Spanish manufacturing firms. Kugler, Jimeno and Hernanz (2003) demonstrate an increase in permanent employment for men under 30 and over 45 years old with a difference in difference analysis of the 1997 reform in Spain. The series of reforms and the large scale nature of temporary work in Spain make it an ideal setting to analyse the effect of contract type on absence. In this way, we extend earlier research on absence and employment protection (Ichino and Riphahn, 2005; Olsson 2009; Scoppa 2010a; Bradley et al. 2014).

Our results suggest that being employed on a permanent contract increases the probability of being absent from work due to sickness by approximately 5.3 percentage points, and increases time absent by approximately 0.30 of a day per week. This estimate is substantially larger than that reported in the previous literature (Ichino and Riphahn, 2005; Olsson, 2009; Scoppa, 2010a; Bradley et al. 2014) and we argue that it is of an economically significant magnitude. Our institutional setting covers an entire labor market, where 
temporary workers may be employed in a variety of occupational and industry settings. While not the focus of our paper we provide evidence that changes in incentives to firms influence the assignment of workers to types of employment contracts across the labor market. We test the sensitivity of our instrumental variable results to violations of the exclusion restriction, i.e. that the reforms do not directly influence absenteeism, using the approach set out by Conley, Hansen and Rossi (2012). Our results add to previous research by providing evidence of employment protection effects on absence in a broader economic and labor market setting.

\section{Institutional background and data}

\section{Institutional background}

Spain's labor market is characterized by high unemployment and high rates of temporary employment; the latter is the highest in Europe (14\% and 33\% in the EU-27 and Spain in 2005, respectively). Figure 1 demonstrates the evolution of the rate of temporary employment in Spain and the countries of the EU-15 and EU-27 (See Dolado, Garcia-Serrano and Jimeno (2002) for a survey on temporary employment in Spain).

$\{\{$ Place Figure 1 about here $\}\}$

Temporary contracts in their modern form were introduced in Spain in 1984 as an attempt to combat high unemployment rates. Specifically, a contract (Contrato temporal de fomento de empleo) was created under which individuals could be hired for a maximum duration of three years, with no constraints. Temporary contracts did exist prior to this (from 1976 on) but were only allowed in very specific jobs that were temporary in nature, such as seasonal work. The 1984 legislative change removed this link between temporary work and job type. This reform led to a large and rapid increase in the use of temporary contracts. While there was no necessary link between job and contract type, in reality the growth in temporary contracts was concentrated in what could be considered low quality jobs. Dismissal of temporary contract workers was relatively easy with no dismissal compensation. In contrast, permanent workers remained very hard to dismiss. Permanent workers must receive 30 days notice of dismissal. If the dismissal is due to objectively bad conduct of the worker there is no further compensation. However, if the dismissal is due to poor demand conditions of the firm, dismissed workers receive 20 days full pay per year worked with the firm up to a maximum of 12 months full pay. If the dismissal is for any other reasons, 
compensation rises to 45 days per year worked with a maximum of 42 months full pay. In practice, most dismissals are not for the first two reasons and maximum compensation is paid. Moreover, if a dismissal was contested by the worker for being unfair and a judgement subsequently was made against the firm (i.e. unfair dismissal) they had to pay full wages for the period between dismissal and trial. This coupled with the relatively slow time to trial in Spain implies a large additional dismissal cost. Together, this helps to explain why temporary contracts proliferated once they were introduced.

The scale of the temporary employment sector generated by the original reform was eventually viewed as undesirable and has led to a number of subsequent reforms aimed at reducing the level of temporary employment, and reducing the size of the disparity between permanent and temporary contract conditions. Of specific interest is the series of reforms that began in 1997. In 1997 a new type of permanent contract was created (Contrato de Fomento de la Contratacion Indefinida, CFCI). The key characteristics were tax breaks for 2 years for firms to hire a worker on this type of contract, and lower potential dismissal costs than standard permanent contracts. The lower dismissal costs of CFCI workers primarily took the form of a lower level of compensation of 33 days full pay per year worked (as compared to 45 for other permanent workers) and a reduction in the maximum period of full pay from 42 to 24 months. Only certain groups of workers could be offered these contracts, 18-29 year olds, workers older than 45 years, long-term unemployed (at least one year), disabled workers and workers currently on temporary contracts within the firm. The eligible groups were subsequently expanded in 2001 to also include 16 and 17 year olds, unemployed women between 16 and 45 years old, those unemployed for at least 6 months and women in sectors where they were under-represented. Another key change that reduced the 'distance' between contract types was that, in certain cases, temporary contract workers were now eligible for dismissal compensation of 8 days.

Further reforms on the $14^{\text {th }}$ of December 2002, extended this contract to women who gave birth in the last 24 months, but also introduced 'express dismissal' (despido express). This lowered dismissal costs of all permanent workers as the employer did not have to pay processing wages if they accepted that the dismissal was unfair within 48 hours, but still had to pay dismissal compensation. Finally in 2006 (active from the $31^{\text {st }}$ December 2006) these CFCIs were extended to cover essentially all workers. In addition, the tax breaks for hiring these workers were changed from a proportion of the wage to a specific amount, which favors 
the hiring of lower wage workers on these contracts. The period of payment of these breaks was also extended from 2 to 4 years. Together these can be seen as progressively inclusive reforms, in terms of coverage, that provide incentives for firms to hire workers on permanent contracts.

In terms of the impact of these reforms on the Spanish labor market, previous research demonstrates that the reforms of the 1990s had a very limited effect on the use of employment contracts in Spain (see for instance Kugler et al. 2003; García Perez and Rebollo, 2009a and 2009b and Mendez, 2012). By the mid-2000s, the share of temporary jobs remained very high and the conversion rate into open-ended contracts remained low and stable at around $4 \%$ of the total number of contracts (Bentolila et al. 2008). Since the approval of the 2006 reform, there has been a substantial reduction in the temporary employment rate but part of the reduction can be attributed to the large destruction of temporary jobs in the construction industry. However, as we demonstrate, the 1997, 2001 and 2002 reforms have an effect on the assignment of workers to contracts by private firms in Spain and this constitutes a key part of our identification strategy. ${ }^{1}$ We choose not to exploit the 2006 reform as it affected all workers.

\section{Data}

The data we use in this paper are drawn from the Longitudinal Spanish Labour Force Survey (herein LSLFS). The LSLFS is a quarterly representative survey that provides a range of information on individual and work characteristics. It is a rotating panel data set that follows individuals for 6 consecutive quarters. It contains 2,592,221 observations for 830,373 different workers in the period spanning $1^{\text {st }}$ quarter of 1996 to $4^{\text {th }}$ quarter of $2008 .^{2}$ The chosen period is crucial for identification purposes since it contains a series of labor market reforms and both the period and the reforms are not associated with any major economic

\footnotetext{
${ }^{1}$ An additional requirement of our identification strategy is that these reforms do not have a direct effect on absenteeism. While a recent reform in 2012 was explicitly aimed at tackling problems related to workplace absenteeism, previous reforms did not have provisions aimed at addressing absenteeism, nor is absenteeism discussed as an issue in these reforms. Moreover, Blázquez (2012) demonstrates that the absence rates and levels of both temporary and permanent workers were stable over the period of 1996-2004.

${ }^{2}$ The Spanish Labour Force Survey has been demonstrated to have an internationally consistent definition of absence (Barmby, Ercolani and Treble, 2002).
} 
crisis. ${ }^{3}$ This makes it less likely that the decrease in temporary employment is due to a general drop in labor demand and employment levels.

While we acknowledge that absenteeism in public sector employment is of interest, and this interest is reflected in previous research (Scoppa 2010b; De Paola, Scoppa and Pupo, 2014), our identification approach is not well suited to the public sector. As the reforms acted to change dismissal costs to employers one might think that profit orientated, private sector, firms may be more responsive to these incentives. ${ }^{4}$ As a result, the paper focuses solely on the private sector where these incentives are likely to be more salient. This reduces our sample to 2,000,614 worker-time observations.

Information on usual and actual hours of work per week forms the basis of our measures of both the extensive and intensive margins of absence. A range of previous literature has demonstrated how answers to usual hours can be used as a proxy for contractual hours (Barmby, Ercolani and Treble, 1999; Lozano, 2011, Green and Navarro, 2012; Shi and Skuterud, 2015). Answers to the actual hours question provides how many hours of work was actually conducted by the individual in the reference week. Hence, combinations of these two variables can be used to create measures of absence, and it has been demonstrated for instance, that this allows internationally comparable measures of absenteeism to be constructed (Barmby et al. 2002).

The extensive absence margin is a variable that takes value 1 when usual hours are greater than actual hours and value 0 if they are the same. The intensive margins of absence are calculated as deviations from contractual hours either in absolute terms or as an absence rate. Hence, the hours a worker is absent per week is calculated as the difference between usual and actual hours, $A_{i t}=H_{i t}^{u}-H_{i t}^{e}$. For ease of interpretation we multiply this number by 60 so that the estimated coefficients are in terms of minutes of absence. The absence rate is defined as the ratio of the hours reported absent to contractual hours in the reference week $A R_{i t}=A_{i t} / H_{i t}^{u}$. Respondents to the LSLFS provide information on the reasons for any difference between usual and actual hours. In our main models we use variation that is

\footnotetext{
${ }^{3}$ Our sample period covers a period of consistent economic growth in Spain and we stop our sample just after the fall of Lehman Brothers which could be considered as the start of the financial crisis.

${ }^{4}$ Indeed, initial trials of our instrumental variable strategy, discussed below, for the public sector were not encouraging. These reforms often have a weak or no effect on the probability of gaining a permanent contract in the public sector.
} 
reported by the worker corresponding to two measures of absenteeism, a broader one, general absence that includes all reasons by which usual and actual hours differ and another one that is restricted to sickness absence only. ${ }^{5}$ This is done for two main reasons. First, while existing literature has generally focussed only on sickness absence, this has been from administrative sources, which in that setting means absence due to sickness with pay (Ichino and Riphahn, 2005; Bradley et al. 2014). In a survey data setting such as ours, it is not clear how an individual who, for instance took time off due to family/personal reasons, but claimed sick pay would respond. Moreover, as our interest is in how effort changes with employment protection, it seems appropriate to consider all variations in absence that may be correlated with contract type as any unplanned (to the firm) deviation from contractual hours may be costly to the firm. The second reason relates to potential inconsistencies in how sickness absence is recorded in the final period of our study (from 2005 on), where there appears to be a drop in the level of recorded sickness absence even where overall general absence remains stable. In this way, our general absence measures provide a valuable robustness check on the sickness absence results.

As an additional restriction, in our main models we only measure negative deviations from contractual hours. In the case where actual hours are greater than usual hours (due to, for instance, overtime) we remove these observations from our sample, leaving a final estimating sample of 1,976,702. Excluding these observations may not be an obvious choice insofar as we are interested in all effort variation due to contract type. Indeed, previous research on Switzerland demonstrates that temporary workers work more unpaid overtime than permanent workers (Engellandt and Riphahn, 2005). However, in unreported results, our main estimates are essentially unaffected by including these positive variations in working time. Moreover, we re-estimated models of contract effects on overtime only and found no evidence that contract type is associated with more, or less, overtime work.

Our choice to examine three dimensions of absenteeism (the extensive margin and two forms of intensive margin) is motivated by a desire to illustrate a broad picture of absence behavior. That is, absenteeism may be higher amongst permanent workers due to it

\footnotetext{
${ }^{5}$ In the Spanish Labour Force Survey if actual hours are reported as less than contractual hours the respondent has to provide one out of sixteen categorical reasons for being absent. In unreported estimates, we also used a broader measure of sickness absence which also includes time off work due to other family and personal reasons. Our main results are robust to using this classification.
} 
being a more frequent phenomenon amongst permanent contract workers or permanent workers taking longer absence spells. At the same time, using the absence rate, in addition to actual time absent, allows us to examine the robustness of our results to underlying variation in contractual hours.

\section{$\{\{$ Place Figure 2 about here $\}\}$}

Figure 2 provides preliminary evidence on the association between general absence and contract type, where the three panels refer to our three measures of absenteeism. To aid with presentation we plot these as 5 year moving averages and show the timing of the four reforms where the 2006 reform is displayed for illustrative purposes. Three things are notable. First there is a marked and stable difference over time in the absence levels of temporary and permanent contract employees. For instance, temporary workers are, on average, absent from work 67 minutes less a week than permanent workers. Second, overall absence levels for both types of workers are high, which reflects the use of all differences in usual and actual hours. The final point relates to the reforms. There doesn't appear to be any visual evidence of a direct relationship between the labor market reforms and the absence behavior of temporary and permanent workers. The contract gaps appear quite similar either side of the four reforms.

Table A1 presents summary statistics on the variables used in the empirical analysis for the whole sample and by permanent and temporary workers, respectively. We show our absence measures, usual and actual hours, along with means for tenure, gender, marital status, education level and age. Not reported, but also included in all models are 9 industry dummies, 8 occupation dummies, 17 region dummies, year dummies and quarter dummies.

\section{Methodology and identification}

The effect of contract type on absence can be estimated as follows:

$A_{i t}=\alpha_{i}+\beta \operatorname{Perm}_{i t}+\eta X_{i t}+\varepsilon_{i t}$,

where $\beta$ provides the conditional effect of working on a permanent contract on the absence of individual $i$ at time $t\left(A_{\mathrm{it}}\right)$. While not the only issue, the chief threat to interpreting this effect as causal is the non-random assignment of workers to permanent contracts. Whilst this may take a number of forms, a salient factor is that firms will be more likely to offer permanent 
contracts to harder working, more productive workers. If these characteristics are omitted from (1) we would expect OLS estimates of the contract effect to be biased downwards. In essence, the permanent contract effect estimate reflects the combination of the behavioral effect (if any) of employment protection on work effort (in expectation higher absence) and the comparison of inherently more productive workers in permanent contracts to less productive, temporary, workers. In an institutional setting such as Spain where dismissal costs are high, and hence there is more strict 'rationing' of permanent contracts one might expect this second source of selection bias to be more severe.

Our identification approach draws upon Kahn (2010) who demonstrates the effect of European employment protection reforms on the incidence of temporary work contracts, and Kugler et al. (2003) who demonstrates how the 1997 reform increased the assignment of younger workers to permanent contracts in Spain. Specifically, we use as exclusion restrictions in the second-stage the effect of the 1997, 2001 and 2002 employment protection reforms for treated workers as a source of exogenous variation in the assignment of contract type. ${ }^{6}$ The standard identifying assumption is that the chosen instrumental variables are relevant and validly excluded. The relevance condition requires that there is a correlation between these reforms for the treatment group $Z$ and the likelihood of permanent employment $E[Z, P e r m] \neq 0$. With respect to the validity condition, our assumption is that our instruments affect workers absence behavior only through its effect on permanent contracts but not directly $E[Z, \varepsilon]=0$. An argument in support of this assumption is that government policy aimed at introducing these new permanent contracts and reducing dismissal costs has had the primary objective of reducing the use of temporary contracts. Although workers' absence leads to significant costs for firms, and in countries like Spain absence levels are very high, governments have generally ignored this aspect when designing employment protection reforms. Furthermore, it has been shown that there is no effect of these EPL reforms on the overall employment level in Spain (Kahn, 2010).

A further concern is that the reforms had two components, tax breaks and also reductions in dismissal costs. The latter component has the potential to directly influence absence behaviour as it represents a reduction in EPL. We acknowledge this point but view the

\footnotetext{
6 Similarly, Dolado et al. (2011) use the 1994, 1997 and 2001/2002 Spanish labour market reforms to identify the exogenous variation in the shares of temporary workers when they evaluate the impact of the extended use of temporary contracts on the productivity of Spanish manufacturing firms.
} 
changes in dismissal costs between 'old' and 'new' permanent contracts as a relatively minor component. As discussed in the previous section, the new permanent contracts are still associated with dismissal costs that are very high even by European standards. Nonetheless, we seek to investigate the sensitivity of our results to this issue using the method developed by Conley et al. (2012). This approach allows for inference even in the situation where the reforms have a direct effect on absenteeism. This works by relaxing the exclusion restriction and providing inference under different assumptions regarding the direct effect of the instruments on our dependent variables of interest.

We present OLS, Fixed Effects, IV and IV-FE estimates of the effect of permanent contracts on worker's absence behavior based on variants of the following specification:

$$
\begin{aligned}
& A_{i t}=\alpha_{i}+\beta \operatorname{Perm}_{i t}+\eta X_{i t}+\varepsilon_{i t}, \\
& \operatorname{Perm}_{i t}=\mu_{i}+\theta_{1} R 1997+\theta_{2} R 2001+\theta_{3} R 2002+\lambda X_{i t}+v_{i t}
\end{aligned}
$$

Where the parameter $\beta$ in equation (2) provides the effect of being employed on a permanent contract, $\operatorname{Perm}_{i t}$, on workers' absence behavior, $A_{i t} \cdot \operatorname{Perm}_{i t}$ is a dummy variable which takes value 1 if the worker is hired on a permanent contract and 0 on a temporary one. Our dependent variable, $A_{i t}$ is measured either at the extensive or the intensive margin of absence (absence incidence versus minutes difference or absence rate). $X$ is a set of standard control variables such as age dummies, gender, marital status, education, tenure, industry, occupation, regional, year and quarter dummies.

Equation (3) provides the relationship between the probability of being employed on a permanent contract to the reforms of 1997, 2001 and 2002. R1997, R2001 and R2002 are dummy variables that take the value of unity for the treatment group after the reform was implemented and zero before implementation. We follow the approach of Kugler et al. (2003) in assigning workers to treatment by relying on age and gender variation in the coverage of each reform. ${ }^{7}$ The treatment group for the 1997 reform are workers 18-29 and older than 45 years old; the treatment group for the 2001 reform are 16-17 year old workers and women in

\footnotetext{
${ }^{7} \mathrm{We}$ do not exploit the changes in coverage in terms of the long term unemployed as this information is not consistently recorded in our data. These data issues are noted in Kugler et al. (2003).
} 
occupations where they were under-represented. ${ }^{8}$ For 2002 the treatment group includes women in the years they are most likely to give birth (25-39 years old) from the $14^{\text {th }}$ of December 2002. As a result, the coefficients $\theta_{1}, \theta_{2}$ and $\theta_{3}$ are interpreted as the average increase in the probability of permanent employment attributable to the legal change.

The estimate of contract effects on absence that we retrieve from (2) is a LATE for compliers. That is, workers who are offered, and take permanent contracts as a result of the reforms. These can be thought of as workers who were viewed as not suitable for permanent contracts under the old regime, but whom are now in expectation productive enough to be offered permanent contracts given the tax breaks and lower dismissal costs. Hence this is both a non-random group of the affected workers, and these workers are likely to have less favorable productivity characteristics than those who would have been offered a permanent contract in the absence of the reform (the always-takers). This leads to an expectation that this LATE will be larger than the estimate of contract effects from OLS. An additional issue is to note that the new permanent contract conditions did not influence those of workers who had already been hired under a permanent contract.

\section{Results}

Table 1 reports estimates of the relationship between permanent contract work and absenteeism, where for brevity we do not report the estimated parameters for the controls but these are available from the authors upon request. ${ }^{9}$ The extensive margin is estimated by Linear Probability Model (LPM) and the intensive margins by OLS. ${ }^{10}$ These estimates provide initial evidence that permanent workers have a statistically significant higher level of sickness absence and absence overall. However, the sickness absence differences are small in magnitude. For instance the OLS estimate of minutes difference between permanent and temporary workers, reveal that permanent workers take 3 more minutes per week off on average. Using a standard 8 hour working day, this is approximately 0.007 of a day per week.

\footnotetext{
${ }^{8}$ Occupations where women are under-represented are defined in the Orden Ministerial of 16 of September 1998.

${ }^{9}$ These covariate estimates follow patterns noted previously in the literature on worker absenteeism.

${ }^{10}$ The sign, magnitude and significance of our estimates were unaffected when we estimated the absence rate with a Tobit model that takes censoring into account. Likewise estimation of the extensive margin by probit does not materially affect our estimates.
} 
These small, but robust, differences are smaller than those reported in previous literature such as Ichino and Riphahn (2005) who observe a 0.04 of a day within worker effect of becoming permanent, or 0.017 of a day in Bradley et al. (2014) study of public sector workers in Australia.

\section{$\{\{$ Place Table 1 about here $\}\}$}

Looking instead at the general absence results, these are substantially bigger, around 49 minutes absence per week difference between temporary and permanent contract workers. This suggests that narrowly focusing on self-reported sickness absence may miss much of the variation in the effect of employment contract on worker absence. In turn, the estimates for general absence provide some initial indication of potentially large productivity differences across contract types. In practice these preliminary differences in absence by contract type may be related to fixed and time varying unobserved differences between workers hired on temporary and permanent contracts. Our estimation strategy seeks to address this by first considering models that include worker level fixed effects before moving on to IV estimation.

Taking into account worker fixed effects reduces the impact of permanent contracts on general absence when compared to the OLS estimates, but remain large and statistically significant, in the order of 28 minutes per week. Again as a way of comparison to existing results the OLS estimate is 0.1 of a day difference in absence per week, while the FE estimate is $0.057 .{ }^{11}$ While smaller than the OLS, this is still larger than thapically reported in the literature. There is also a diminution of coefficient size between OLS and FE for the extensive margin and the absence rate. For sickness absence this pattern is less clear, while there are statistically significant differences by contract type, contract estimates for all absence measures are essentially unchanged across OLS and FE estimation.

\section{$\{\{$ Place Table 2 about here $\}\}$}

One natural concern is the comparability of temporary and permanent workers. Temporary and permanent contracts are not randomly distributed across the Spanish labor market and one particular further concern may be that there is substantial selection into contract status on the basis of time varying unobservables. This will lead to biased estimates of contract effects on absenteeism. With this in mind we now proceed to our instrumental

\footnotetext{
${ }^{11}$ Based on a standard working day of 8 hours.
} 
variable strategy where we exploit labor reforms as a source of exogenous variation in the assignment to contract type.

Table 2 reports the instrumental variable estimates. The first stage estimates, which provide the effect of each reform on the probability of gaining a permanent contract, are informative in themselves. The 1997 reform (30 ${ }^{\text {th }}$ of December 1997, first quarter of 1998), through the reduction of payroll taxes and dismissal costs, increased the conversion of temporary into permanent contracts for young (18-29 years old) and older workers $(+45$ years old) compared to workers in the middle age group (30-44 years old). The effect is a 2 percentage point increase. This is similar to the estimates reported by Kugler et al. (2003) for the same reform in the order of 2.5 percentage points. We go further and show that all three reforms led to an increase in the likelihood of gaining a permanent contracted job. Specifically, the 2001 reform $\left(11^{\text {th }}\right.$ of July $2001,3^{\text {rd }}$ quarter 2001$)$ led to an increase in 2.6 percentage points. The 2002 reform (14 ${ }^{\text {th }}$ of December 2002, first quarter of 2003) also increased movement into permanent contracts but had a smaller effect of just 0.7 percentage points. This fits expectations insofar as the 2002 reform can be viewed as a minor extension of the previous two reforms. These results are interesting in themselves as they show how the reforms had incentive effects on private sector firms influencing their willingness to offer permanent contracts. In terms of diagnostics, our instruments are strong predictors of contract type. However, the Hansen-test leads us to reject the null hypothesis of the instruments being validly excluded from the absence equations. We return to this point later and examine the robustness of our results to relaxing this assumption.

Panel B of Table 2 reports the resultant IV estimates of permanent contract effects on absence. When compared to previous OLS and FE estimates these are markedly larger. For instance, the general absence effect on minutes absence is 8 times larger than the OLS and 10 times larger in the estimate for the extensive margin. To be specific, the impact of permanent contract on general absence is that of six hours per week, this is equivalent to three quarters of a working day. IV estimates of the contract effect on minutes of sickness absence are of smaller magnitudes but substantially larger than the OLS estimates. These are in the order of 147 minutes difference per week. Estimates of the extensive margin and absence rate for sickness absence remain positive but are imprecise. As discussed earlier, the larger estimated effects may reflect both the downward bias of the OLS estimates and the Local Average 
Treatment Effect (LATE) interpretation of the IV estimates. We investigate these issues with interpretation more fully later.

Table A2 provides analogous IV-FE estimates of contract effects on absence. Note that approximately 100,000 individuals are dropped from the estimating sample as they are only observed once in the data. The first stage estimates of the effect of the reforms on the probability of being hired on a permanent contract are similar to those reported in Table 2 . The resultant IV-FE estimates, while consistent with the earlier IV estimates, are of a smaller magnitude.

\section{$\{\{$ Place Table 3 about here $\}\}$}

To this point we have found effects that are substantially larger than cohort based studies that examine early career workers without employment protection as they gain more permanent work. While we have limited our sample to temporary workers, this still includes workers with longer tenure and tenure is a known positive correlate of absenteeism with a non-linear relationship (Bradley et al. 2014), and permanent workers have markedly higher average tenure than temporary workers in our sample (130 months versus 19 months). Initially, we re-estimated our main models including an interaction between tenure and permanent contract. These interaction terms were typically not statistically significant at standard levels, and never of economically substantive magnitudes. To examine this further, we limit our sample first to those workers with less than 5 years of tenure, and then those with less than 2 years of tenure. In this sense, this sample is closer to existing studies that look at new workers without employment protection. Insofar as these studies have demonstrated smaller effects than our estimates, this may hinge on factors such as relatively strong career concerns early in employment that serve to reduce all workers absence irrespective of employment protection. With this in mind, we restrict our sample by tenure of the worker in their first period of observation in the sample. We begin initially with those up to 5 years of tenure and this is followed by a sample of those with less than 2 years of tenure. At the same time, we acknowledge that this approach is not ideal insofar as tenure and contract status are co-determined.

Our re-estimated IV models on these restricted samples are reported in Table 3. The first thing to note is that the first stage coefficients for the reforms become larger, and in general increase as we look at more narrow tenure groups of workers. This can be interpreted as showing that the effect of the reform was concentrated heavily in short tenure workers. Again 
this is interesting as it provides a suggestion of which types of workers were most readily affected by these reforms. We report IV-FE estimates in Table A3. These, again, are consistent with the IV estimates in terms of sign and statistical significance, but are in some cases larger in magnitude.

In terms of the absence estimates, these are generally much lower in the restricted tenure estimates compared to all workers. For instance, for workers with less than 2 years tenure the general absence effect of permanent work is 100 minutes, just over a quarter of the size of the estimate reported in table 2. However, there is little difference between those with less than 5 years and those with less than 2 years. Moreover, there are more muted differences between estimates of contract effects on sickness absence across the full sample and the two subsamples. The corresponding estimates for the extensive margin and absence rate are between 0.017 and 0.078 .

Again we can use these estimates to compute weekly loss of time due to absence as a result of moving into a permanent contract. For workers with less than 5 years tenure this amounts to approximately 0.225 of a day per week in general absence, of which 0.123 is absence reported as being due to sickness. For workers with less than 2 years tenure it ranges between 0.209 of a day for general absence, and 0.080 for sickness absence. Even in this very narrow tenure window our general absence effect is almost twice of that reported by the least conservative current estimates in the literature (Ichino and Riphahn, 2005). Moving to the 5 year tenure group the general absence effect of being employed on a permanent contract is over 5 times larger than that reported in Ichino and Riphahn (2005), and over ten times larger than that reported in Bradley et al. (2014). Our feeling is that our empirical strategy reveals substantial effects of contract status on absence, and insofar as this is a proxy for effort, productivity. This suggests that variations in employment protection can have marked effects on productivity both within countries, and potentially, cross-country.

We further explore the robustness of our IV estimation. Specifically, we focus on three points. First, the result from employing all 3 policy instruments together (minutes difference $=100.376$ (s.e. 25.693) and absence rate $=0.048$ (s.e. 0.011) should correspond to a weighted average of IV estimates where each instrument is introduced individually. The initial panel of Table 4 reports the results from doing this and demonstrate that this, in essence, holds.

Second, we recognize that for our reforms to influence absenteeism through contract type there needs to be a direct effect of these reforms for the treated group on absenteeism. We 
investigate this by estimating the reduced form intention to treat (ITT) effect of the reforms on the treated group's absence using the difference-in-difference approach along the lines set out in (3). The resultant coefficients for each reform are reported in Table 4. These demonstrate ITT estimates of a positive impact of each reform on worker absence.

$\{\{$ Place Table 4 about here $\}\}$

A related concern is that the IV estimated coefficients remain large. This may be related to the proportion of compliers in the first stage estimates being small. In this case, it can be shown that the causal effect of permanent contracts on absence is the ITT effect (reduced form) divided by the first-stage or the compliance rate in the originally assigned treatment group. In this way, the second stage estimates can be viewed as a re-scaling of the reduced form (Angrist and Pischke, 2009; Angrist and Krueger, 2001). Hence, the large estimates for the 2002 reform reflect both a larger ITT effect but also a relatively low compliance rate. For instance, this reform was targeted at women who had given birth in the last 24 months. This is reflected in an estimated compliance rate of $1.8 \%$ which is substantially smaller than those reported for the other two reforms (5.8\% and 7\%, respectively).

\section{Plausible Exogeneity}

Given that the instruments do not pass standard tests of validity, although the reforms were not designed with absenteeism or effort explicitly in mind, one may still be concerned that changes in the structure of employment protection in some way directly influence absence behavior. For instance, it may change the expected cost of detected shirking if there is an influence on outflows from unemployment.

Likewise, as we note earlier the very nature of the reforms led to some lowering of dismissal costs associated with some permanent contracts, and this could influence absence behavior of permanent workers. We seek to examine the effect of potential violations of the exclusion of our reforms from the absence equations using the plausible exogeneity bounds estimator developed by Conley et al. (2012). This method seeks to assess whether it is possible to provide meaningful estimates in the scenario where the instruments may not be validly excluded.

$\{\{$ Place Table 5 about here $\}\}$ 
Consider the following absence equation, where $Z$ is our instrument vector (labor market reforms for the corresponding treatment groups):

$$
A_{i t}=\alpha_{i}+\beta P e r m_{i t}+\eta X_{i t}+\gamma Z_{i t}+\varepsilon_{i t}
$$

Conley et al. (2012) demonstrates that it is possible to provide informative inference even when there are large deviations from the exclusion restriction. Specifically, provided the instrument is strong, violation of the exclusion restrictions results only in a loss of precision. They develop different methods that combine information in the data with priors about $\gamma$, where valid exclusion $(\gamma=0)$ is a special case, to provide valid inference regarding $\beta$. We adopt two approaches and the results are reported in Table 5. In the first case, we use the local-to-zero method that employs priors with respect to the mean and variance-covariance matrix structure of $\gamma$ to construct $95 \%$ confidence intervals for the effect of permanent contracts on absenteeism. This is designed to produce an asymptotic approximation in which both sampling error and uncertainty regarding $\gamma$ play a role. The resultant approximation is the sum of the usual asymptotic distribution and an additional random variable which arises from the prior over $\gamma$. The second approach we use is the Union of Confidence intervals approach (UCI) where 95\% confidence intervals for $\beta$ are obtained conditional on any potential value of $\gamma$. Taking the union of these interval estimates across different $\gamma$ values provides a conservative interval estimate for $\beta$. For both methods and for general and sickness absence, our estimates of the effect of permanent contracts on minutes difference remains significantly greater than zero at the $95 \%$ confidence level. Our estimates of the extensive margin and absence rate are less precise perhaps reflecting their limited dependent variable nature. Nonetheless when we use the local to zero approximation approach, these remain above zero at the $95 \%$ level (general absence) and at the $90 \%$ confidence level (sickness absence). These estimates suggest that, even in the case where our instruments are not validly excluded, under reasonable priors the likely effect of permanent contracts on worker absence is significantly greater than zero. However, using the UCI approach the lower bound confidence intervals for these absence measures overlap zero for both general and sickness absence. This provides a cautionary note with respect to our IV estimates of the effect of permanent contracts on both the extensive margin and the absence rate. ${ }^{12}$

\footnotetext{
${ }^{12}$ Table A4 provides corresponding estimates for our shorter tenure sub-samples. These essentially follow those reported in table 5, however, the local to zero approximation results are typically more precise.
} 


\section{Conclusion}

The strong employment protection found in many areas of Europe has the potential to dramatically influence labor market performance and outcomes. For instance, a large literature has demonstrated the effects of these regimes on labor productivity and unemployment. The behavioral effect of employment protection on workers is less well understood. A recent literature has developed examining how employment protection conditions worker effort. This research has shown an effect of employment protection on absenteeism, but one that appears too small in magnitude to generate large differences in labor productivity. In practice, identifying causal effects of employment protection on effort is difficult, especially in a broad labor market setting. Our paper used a combination of within worker estimation and legislative changes in Spain as a source of exogenous variation in contract type to identify this effect.

We demonstrate large effects of temporary contract on worker absence. This finding is robust to a range of sub-samples, and attempts to address issues related to the appropriate control group, and concerns over the validity of our exclusion restriction. This evidence demonstrates that variations in employment protection can have a marked effect on worker effort. In seeking to provide causal estimates of the effect of contract type on absenteeism we have used reforms that target specific sub-groups to attain LATE estimates. This raises standard concerns regarding the external validity of our results. Nonetheless, we feel that they indicate the potential for an effect of employment protection on cross-country variations in labor productivity. It also suggests that firms will factor in this behavioral aspect of employment protection as part of the decision of offering permanent, versus temporary, contracts. This may also indicate the need for firms to pursue other incentives for permanent workers such as performance pay, deferred compensation or the like which either implicitly or explicitly deter absenteeism. Future research could consider whether there is evidence of complementarity between these types of compensation methods and the use of permanent contracts. 


\section{References}

Acemoglu, Daron, and Joshua Angrist. 2001. Consequences of employment protection? The case of the Americans with disabilities act. Journal of Political Economy, 109: 915-57.

Addison, John T., Paulino Teixera and Jean-Luc Grosso. 2000. The effect of dismissals protection on employment: More on a vexed theme. Southern Economic Journal, 67(1): 105-122.

Aghion, Phillippe, Richard Blundell, Rachel Griffith, Peter Howitt, and Susanne Prantl. 2004. Entry and productivity growth: Evidence from microlevel panel data. Journal of the European Economic Association, 2(2-3): 265-76.

Angrist, Joshua D., and Jörn-Steffen Pischke. 2009. Mostly Harmless Econometrics: An Empiricist's Companion. Princeton University Press. New Jersey.

Angrist, Joshua D., and Alan B. Krueger. 2001. Instrumental variables and the search for identification: From supply and demand to natural experiments. Journal of Economic Perspectives, 15(4): 69-85.

Arulampalam, Wiji, and Alison L. Booth. 1998. Training and labour market flexibility: Is there a trade-off? British Journal of Industrial Relations, 36(4): 521-36.

Barmby, Tim, Marco Ercolani, and John Treble. 1999. Sickness absence in Great Britain: new quarterly and annual series from the GHS and LFS, 1971-1997. Labour Market Trends, 405-15.

Barmby, Tim, Marco Ercolani, and John Treble. 2002. Sickness absence: An international comparison. Economic Journal, 112: F315-F331.

Bassanini, Andrea, Luca Nunziata and Danielle Venn. 2009. Job protection legislation and productivity growth in OECD countries. Economic Policy, 24: 349-402.

Bentolila, Samuel, Juan J. Dolado, and Juan F. Jimeno. 2008. Two-tier employment protection reforms: The Spanish experience. CESifo DICE Report 4/2008, 49-56. www.cesifo.de

Blanchard, Olivier and Pedro Portugal. 2001. What hides behind an unemployment rate: Comparing Portuguese and U.S. labor markets. American Economic Review, 91(1): 187207.

Blázquez, Maite. 2012. Sickness absence rates in Spain- Evidence for the period 1996-2004. Cuadernos de Economía, 35: 1-8. 
Booth, Alison L., Francesconi, Marco and Jeff Frank. 2002. Temporary jobs: Stepping stones or dead ends? Economic Journal, 112(480): F189-F213.

Bradley, Steve, Colin Green, and Gareth Leeves. 2014. Employment protection, threat and incentive effects on worker absence. British Journal of Industrial Relations, 52(2): 333358.

Cappellari, Lorenzo, Carlo Dell'Aringa and Marco Leonardi. 2012. Temporary employment, job flows and productivity: A tale of two reforms. Economic Journal, 122, F188-F215.

Conley, Timothy G., Christian B. Hansen, and Peter E. Rossi. 2012. Plausibly exogenous. Review of Economics and Statistics, 94: 260-272.

De Paola, Maria, Vincenzo Scoppa, and Valeria Pupo. 2014. Absenteeism in the Italian public sector: The effects of changes in sick leave policy. Journal of Labor Economics, 32(2): 337-360.

Dolado, Juan J. and Rodolfo Stucchi. 2008. Do temporary contracts affect total factor productivity? Evidence from Spanish manufacturing firms. CEPR Discussion Papers, 7055.

Dolado, Juan J., Carlos Garcia-Serrano, and Juan F. Jimeno. 2002. Drawing lessons from the boom of temporary jobs in Spain. Economic Journal, 112(480): F270-F295.

Dolado, Juan J., Salvador Ortigueira and Rodolfo Stucchi. 2011. Does dual employment protection affect TFP? Evidence from Spanish manufacturing firms. Economics Working Papers 11-37 Universidad Carlos III.

Draca, Mirko and Colin Green. 2004. The incidence and intensity of employer funded training: Australian evidence on the impact of flexible work. Scottish Journal of Political Economy, 51(5): 609-25.

Engellandt, Axel and Regina T. Riphahn. 2005. Temporary contracts and employee effort. Labour Economics, 12: 281-99.

García Pérez, José Ignacio, and Yolanda Rebollo. 2009a. The use of permanent contracts across Spanish regions: do regional wage subsides work? Investigaciones Económicas, XXXIII(1): 97-130.

García Pérez, José Ignacio, and Yolanda Rebollo. 2009b. Do wage subsidies affect the subsequent employment stability of permanent workers?: the case of Spain. Moneda $y$ Crédito, 228: 65-103.

Green, Colin and Gareth Leeves. 2004. Casual jobs and internal labour markets. Manchester School, 72(5): 658-676. 
Green, Colin and Maria Navarro. 2012. Does raising the school leaving age reduce teacher effort? Evidence from a policy experiment. Economic Inquiry, 50(4): 1018-30.

Guadalupe, Maria. 2003. The hidden costs of fixed term contracts: the impact on work accidents. Labour Economics, 10(3): 339- 57.

Güell, Maia and Barbara Petrongolo. 2007. How binding are legal limits? Transitions from temporary to permanent work in Spain. Labour Economics, 14: 153-83.

Ichino, Andrea and Regina Riphahn. 2004. Absenteeism and employment protection: Three case studies. Swedish Economic Policy Review, 11: 95-114.

Ichino, Andrea and Regina Riphahn. 2005. The effect of employment protection on worker effort: A comparison of worker absenteeism during and after probation. Journal of European Economic Association, 3: 120-143.

Jimeno, Juan F. and Luis Toharia. 1996. Effort, absenteeism, and fixed term employment contracts. Spanish Economic Review, 13(1): 105-19.

Kahn, Lawrence M. 2007. The impact of employment protection mandates on demographic temporary employment patterns: international microeconomic evidence. Economic Journal, 117: F333-F356.

Kahn, Lawrence M. 2010. Employment protection reforms, employment and the incidence of temporary jobs in Europe: 1996-2001. Labour Economics, 17: 1-15.

Kugler, Adriana and Giovanni Pica. 2008. Effects of employment protection on worker and job flows: Evidence from the 1990 Italian reform. Labour Economics, 15: 78-95.

Kugler, Adriana., Juan F. Jimeno, and Virginia Hernanz. 2003. Employment consequences of restrictive permanent contracts: Evidence from Spanish labor market reforms. CEPR Discussion Papers, 3724.

Lazear, Edward P. 1990. Job security provisions and employment. The Quarterly Journal of Economics, 105(3): 699-726.

Lozano, Fernando A. 2011. The flexibility of the workweek in the United States: Evidence from the FIFA World Cup. Economic Inquiry, 49(2): 512-29.

Mendez, Ildefonso. 2012. Promoting permanent employment: Lessons from Spain. SERIEs, 4(2): 175-99.

Olsson, Martin. 2009. Employment protection and absence. Labour Economics, 16: 208-14.

Prescott, Edward C. 2004. Why do Americans work so much more than Europeans? Federal Reserve Bank of Minneapolis Quarterly Review, 28(1): 2-13. 
Riphahn, Regina and Anja Thalmaier. 2001. Behavioral effects of probation periods: An analysis of worker absenteeism. Journal of Economics and Statistics, 221(2): 179-201.

Shi, Jingye, and Mikal Skuterud. 2015. Gone fishing! Reported sickness absenteeism and the weather. Economic Inquiry, 53(1): 388-405.

Scoppa, Vincenzo. 2010a. Shirking and employment protection legislation: Evidence from a natural experiment. Economics Letters, 107: 276-80.

Scoppa, Vincenzo. 2010b. Worker absenteeism and incentives: evidence from Italy. Managerial and Decision Economics, 31(8): 503-15.

Timmer, Marcel P., and Bart van Ark. 2005. Does information and communication technology drive EU-US productivity growth differentials? Oxford Economic Papers, 57(4): 693-716.

Van Ark, Bart., Mary O’Mahony and Marcel P. Timmer. 2008. The productivity gap between Europe and the United States: Trends and causes. The Journal of Economic Perspectives, 22(1): 25-44. 
Figure 1. Temporary employees as percentage of the total number of employees in Spain, the EU-15 and EU-27 (SOURCE: EUROSTAT and Spanish Labour Force Survey)

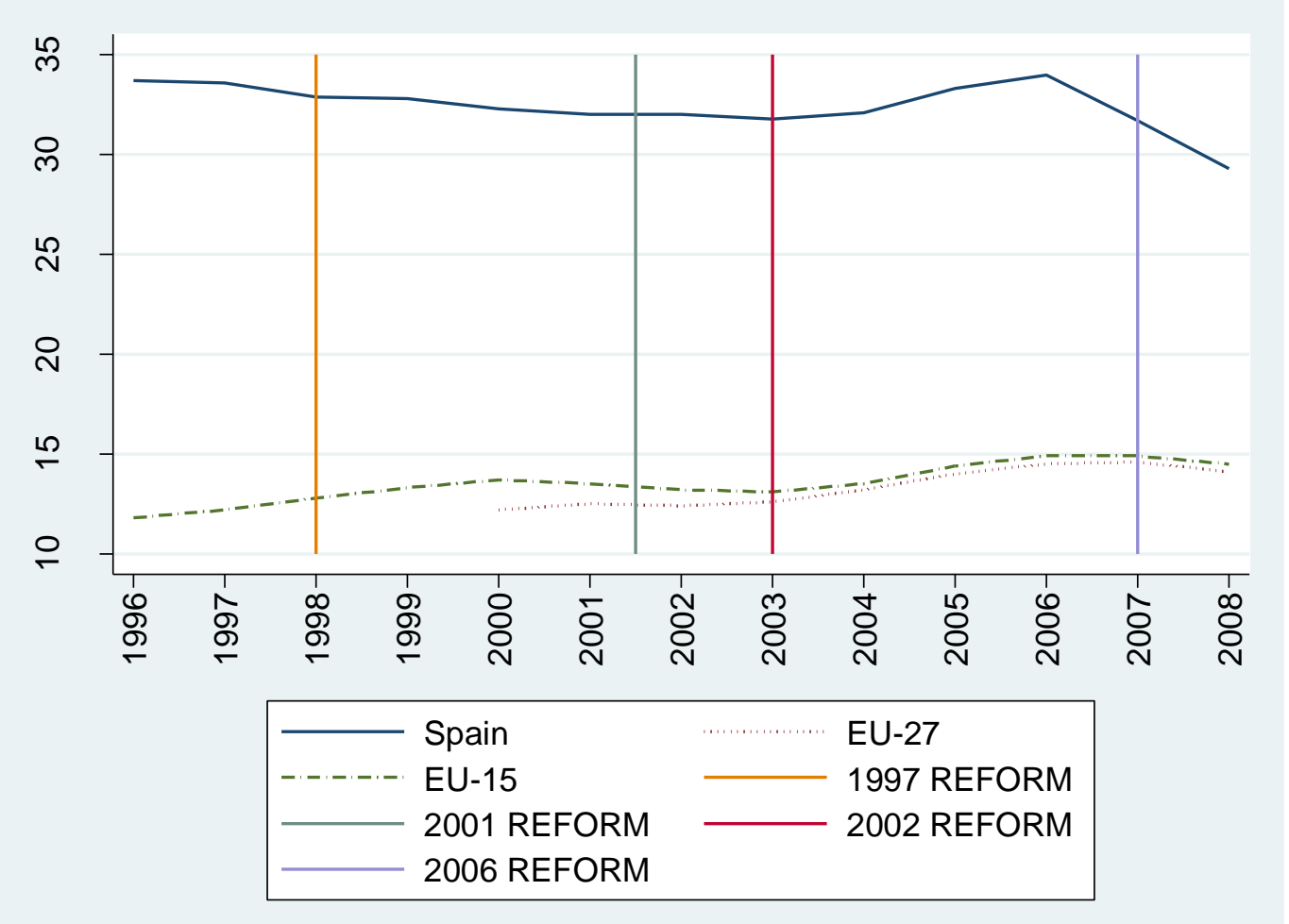


Figure 2. Absenteeism and Contract Type, Spain, 1994 - 2008 Private Sector Workers (SOURCE: Spanish Labour Force Survey)

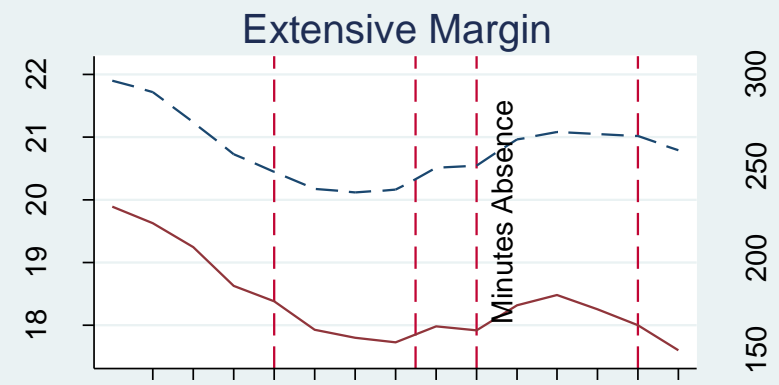

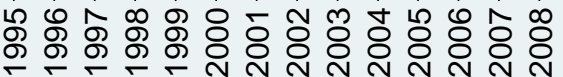

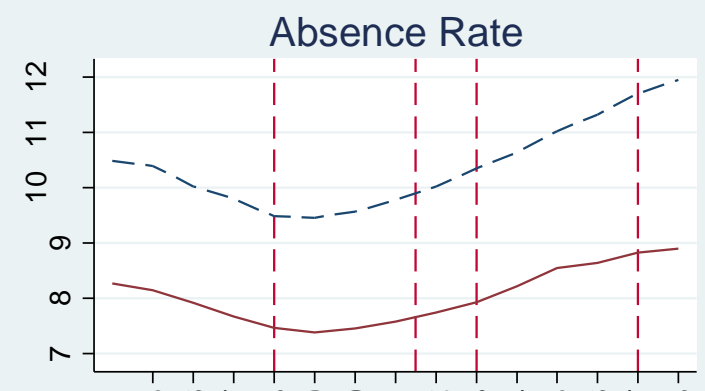

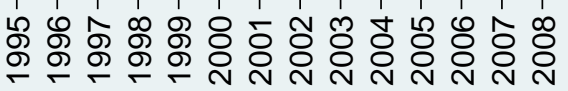

Minutes Absence

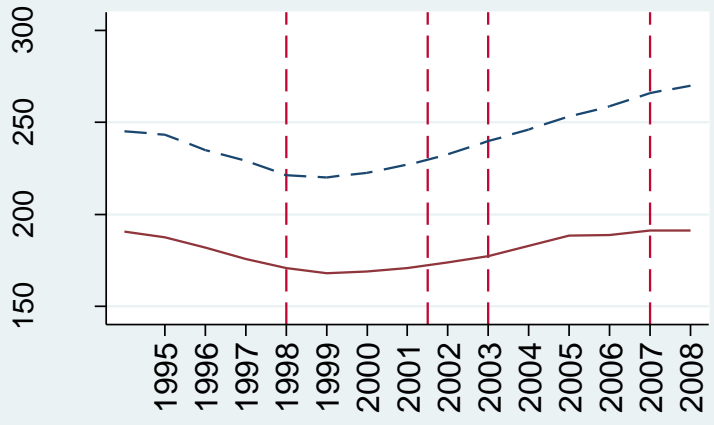

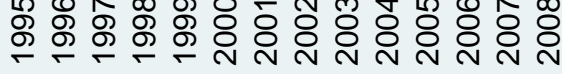

- - - - Permanent Temporary 
Table 1. Permanent Contracts and Absence, Spain 1996-2008, OLS and FE Estimates, Private Sector Workers.

\begin{tabular}{lcccc}
\hline & \multicolumn{2}{c}{ OLS } & \multicolumn{2}{c}{ FE } \\
\hline & $\begin{array}{c}\text { General } \\
\text { Absence }\end{array}$ & $\begin{array}{c}\text { Sickness } \\
\text { Absence }\end{array}$ & $\begin{array}{c}\text { General } \\
\text { Absence }\end{array}$ & $\begin{array}{c}\text { Sickness } \\
\text { Absence }\end{array}$ \\
\hline Extensive margin & $0.018 * * *$ & $0.001 * * *$ & $0.008 * * *$ & $0.001 * *$ \\
& $(0.001)$ & $(0.000)$ & $(0.002)$ & $(0.001)$ \\
Minutes diff & $48.980 * * *$ & $3.181 * * *$ & $27.676 * * *$ & $3.206 * * *$ \\
& $(1.008)$ & $(0.529)$ & $(2.506)$ & $(0.993)$ \\
Absence rate & $0.018 * * *$ & $0.001 * * *$ & $0.012 * * *$ & $0.002 * * *$ \\
& $(0.000)$ & $(0.000)$ & $(0.001)$ & $(0.000)$ \\
Observations & & \multicolumn{2}{c}{1976702} & \\
Number of Workers & & \multicolumn{2}{c}{664705} &
\end{tabular}

Note: Robust standard errors in parentheses. ***, and ** indicate statistical significance at the 0.01 and 0.05 level, respectively. All models include controls for gender, marital status, education, age, tenure, regions, years, occupation and industry. Each cell corresponds to estimates for the various absence definitions. The coefficient corresponds to the variable permanent contract. 
Table 2. IV Estimates of the Effect of Permanent Contracts on Absence, Private Sector Workers 1996-2008.

\begin{tabular}{lcc}
\hline Panel A & \multicolumn{2}{c}{ Permanent Contract } \\
First-Stage & \multicolumn{2}{c}{$0.020^{* * *}$} \\
\hline R 1997 0.003$)$ \\
R 2001 & \multicolumn{2}{c}{$0.026^{* * *}$} \\
& \multicolumn{2}{c}{$(0.004)$} \\
R 2002 & \multicolumn{2}{c}{$0.007 * * *$} \\
& \multicolumn{2}{c}{$(0.002)$} \\
Partial R-squared & \multicolumn{2}{c}{0.0001} \\
F-test of excl. & \multicolumn{2}{c}{26.29} \\
p-value & \multicolumn{2}{c}{0.0000} \\
Hansen test & 216.363 & 121.913 \\
p-value & 0.0000 & 0.0000 \\
\hline Panel B & \multicolumn{2}{c}{ Sickness } \\
Second-Stage & General & Absence \\
IV & Absence & $0.053^{*} *$ \\
Extensive margin & $0.186 * * *$ & $(0.027)$ \\
& $(0.071)$ & $146.554^{*} * *$ \\
Minutes diff & $412.298^{* * *}$ & $(56.627)$ \\
& $(108.700)$ & 0.035 \\
Absence rate & $0.180^{* * *}$ & $(0.025)$ \\
Observations & $(0.047)$ & 1976702 \\
\hline
\end{tabular}

Note: Robust standard errors in parentheses. ***, and ** indicate statistical significance at the 0.01 and 0.05 level, respectively. All models include controls for gender, marital status, education, age, tenure, regions, years, occupation and industry. 
Table 3. IV Estimates of the Effect of Permanent Contracts on Absence, Private Sector Workers 1996-2008. (Tenure <5yrs, Tenure <2yrs).

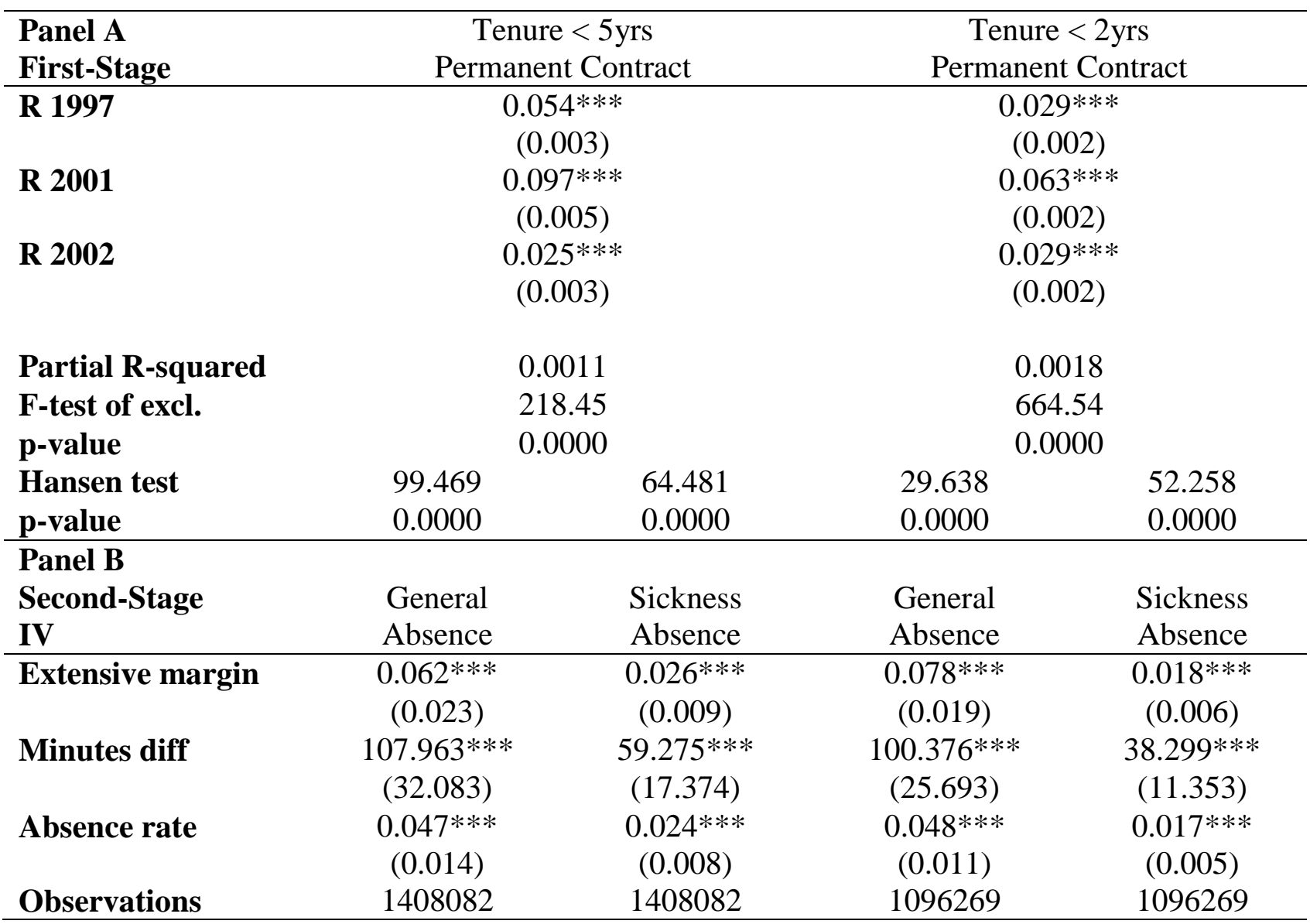

Note: Robust standard errors in parentheses. $* * *$ indicates statistical significance at the 0.01 level. All models include controls for gender, marital status, education, age, tenure, regions, years, occupation and industry. 
Table 4. Reduced forms, first stages and IV estimates for each reform separately

\begin{tabular}{|c|c|c|c|}
\hline \multirow[t]{2}{*}{ Panel A } & \multicolumn{3}{|c|}{ Extensive margin } \\
\hline & R 1997 & R 2001 & R 2002 \\
\hline \multirow{4}{*}{$\begin{array}{l}\text { Reduced form } \\
\text { (ITT) } \\
\text { First stage }\end{array}$} & $0.003 *$ & $0.004 * * *$ & $0.007 * * *$ \\
\hline & $(0.002)$ & $(0.001)$ & $(0.002)$ \\
\hline & $0.058 * * *$ & $0.070 * * *$ & $0.018 * * *$ \\
\hline & $(0.002)$ & $(0.002)$ & $(0.002)$ \\
\hline \multirow{2}{*}{ IV } & $0.059^{*}$ & $0.058 * * *$ & $0.375 * * *$ \\
\hline & $(0.030)$ & $(0.021)$ & $(0.096)$ \\
\hline \multirow[t]{2}{*}{ Panel B } & \multicolumn{3}{|c|}{ Minutes difference } \\
\hline & R 1997 & R 2001 & R 2002 \\
\hline Reduced form & $4.716 * *$ & $3.307^{*}$ & $14.321 * * *$ \\
\hline (ITT) & $(2.367)$ & $(1.982)$ & $(2.356)$ \\
\hline \multirow[t]{2}{*}{ First stage } & $0.058 * * *$ & $0.070 * * *$ & $0.018 * * *$ \\
\hline & $(0.002)$ & $(0.002)$ & $(0.002)$ \\
\hline \multirow[t]{2}{*}{ IV } & $82.076^{* *}$ & $47.300^{*}$ & $772.905^{* * *}$ \\
\hline & $(41.218)$ & $(28.337)$ & $(151.694)$ \\
\hline \multirow[t]{2}{*}{ Panel C } & \multicolumn{3}{|c|}{ Absence rate } \\
\hline & R 1997 & R 2001 & R 2002 \\
\hline Reduced form & $0.002 *$ & $0.002 * *$ & $0.007 * * *$ \\
\hline$($ ITT $)$ & $(0.001)$ & $(0.001)$ & $(0.001)$ \\
\hline \multirow{2}{*}{ First stage } & $0.058 * * *$ & $0.070 * * *$ & $0.018 * * *$ \\
\hline & $(0.002)$ & $(0.002)$ & $(0.002)$ \\
\hline \multirow[t]{2}{*}{ IV } & $0.034^{*}$ & $0.025 * *$ & $0.361 * * *$ \\
\hline & $(0.018)$ & $(0.012)$ & $(0.068)$ \\
\hline
\end{tabular}

Note: Robust standard errors in parentheses. $* * *, * *$ and $*$ indicate statistical significance at the $0.01,0.05$ and 0.10 level, respectively. All models include controls for gender, marital status, education, age, tenure, regions, years, occupation and industry. 
Table 5. Plausible Exogeneity and the Effect of Permanent Contracts on Absence, Private Sector Workers.

\begin{tabular}{lccccc}
\hline & \multicolumn{2}{c}{ Local to zero approximation } & \multicolumn{2}{c}{ UCI (95\%) } \\
& Coeff & $\begin{array}{c}\text { 95\% Confidence } \\
\text { interval }\end{array}$ & $\begin{array}{c}\text { Lower } \\
\text { bound }\end{array}$ & $\begin{array}{c}\text { Upper } \\
\text { bound }\end{array}$ \\
\hline General Absence & & & & & \\
Extensive margin & 0.186 & {$\left[\begin{array}{llll}0.005 & 0.367\end{array}\right]$} & -0.514 & 0.909 \\
Minutes difference & 434.872 & {$\left[\begin{array}{llll}170.924 & 698.820\end{array}\right]$} & 171.309 & 375.516 \\
Absence rate & 0.182 & {$\left[\begin{array}{llll}0.067 & 0.297\end{array}\right]$} & -0.4737 & 0.8677 \\
Sickness Absence & & & & \\
Extensive margin & 0.053 & {$\left[\begin{array}{llll}-0.007 & 0.112\end{array}\right]$} & -0.591 & 0.707 \\
Minutes difference & 144.064 & {$\left[\begin{array}{llll}30.395 & 257.733\end{array}\right]$} & 4.674 & 57.573 \\
Absence rate & 0.036 & {$\left[\begin{array}{lll}-0.016 & 0.087\end{array}\right]$} & -0.569 & 0.649 \\
\hline Note: All models include controls for gender, marital status, education, age, tenure, regions, years, occupation and industry.
\end{tabular}


Table A1. Descriptive Statistics, Spain 1996-2008

\begin{tabular}{|c|c|c|c|}
\hline Variables & All workers & Temporary & Permanent \\
\hline \multicolumn{4}{|l|}{ General Absence } \\
\hline \multirow[t]{2}{*}{ Extensive margin } & 0.197 & 0.179 & 0.206 \\
\hline & $(0.397)$ & $(0.384)$ & $(0.404)$ \\
\hline \multirow[t]{2}{*}{ Minutes diff } & 223.134 & 179.856 & 246.737 \\
\hline & $(579.327)$ & $(498.730)$ & $(617.599)$ \\
\hline \multirow[t]{2}{*}{ Absence rate } & 0.098 & 0.081 & 0.108 \\
\hline & $(0.254)$ & $(0.223)$ & $(0.269)$ \\
\hline \multicolumn{4}{|l|}{ Sickness absence } \\
\hline \multirow[t]{2}{*}{ Extensive margin } & 0.017 & 0.015 & 0.019 \\
\hline & $(0.131)$ & $(0.123)$ & $(0.135)$ \\
\hline \multirow[t]{2}{*}{ Minutes diff } & 29.426 & 26.115 & 31.231 \\
\hline & $(249.965)$ & $(235.111)$ & (257.688) \\
\hline \multirow[t]{2}{*}{ Absence rate } & 0.014 & 0.012 & 0.014 \\
\hline & $(0.111)$ & $(0.104)$ & $(0.114)$ \\
\hline \multirow[t]{2}{*}{ Usual minutes } & 2323.781 & 2242.679 & 2368.013 \\
\hline & (531.969) & $(611.159)$ & $(477.574)$ \\
\hline \multirow[t]{2}{*}{ Actual minutes } & 2100.647 & 2062.823 & 2121.275 \\
\hline & (776.299) & $(764.772)$ & (781.744) \\
\hline \multicolumn{4}{|l|}{ Permanent } \\
\hline \multirow[t]{2}{*}{ contract } & 0.647 & 0.000 & 1.000 \\
\hline & $(0.478)$ & $(0.000)$ & $(0.000)$ \\
\hline \multirow[t]{2}{*}{ Tenure (months) } & 92.384 & 18.803 & 130.472 \\
\hline & (112.450) & $(37.950)$ & (119.129) \\
\hline \multirow[t]{2}{*}{ Female } & 0.376 & 0.400 & 0.364 \\
\hline & $(0.484)$ & $(0.490)$ & $(0.481)$ \\
\hline \multirow[t]{2}{*}{ Married } & 0.551 & 0.387 & 0.640 \\
\hline & $(0.497)$ & $(0.487)$ & $(0.480)$ \\
\hline \multirow[t]{2}{*}{ Primary Educ } & 0.475 & 0.494 & 0.465 \\
\hline & $(0.499)$ & $(0.500)$ & $(0.499)$ \\
\hline \multirow[t]{2}{*}{ Second Educ } & 0.269 & 0.283 & 0.261 \\
\hline & $(0.443)$ & $(0.450)$ & $(0.439)$ \\
\hline \multirow[t]{2}{*}{ Higher Educ } & 0.256 & 0.223 & 0.274 \\
\hline & $(0.437)$ & $(0.417)$ & $(0.446)$ \\
\hline \multirow[t]{2}{*}{ Age 16-19 } & 0.032 & 0.076 & 0.008 \\
\hline & $(0.176)$ & $(0.264)$ & $(0.090)$ \\
\hline \multirow[t]{2}{*}{ Age $20-24$} & 0.127 & 0.233 & 0.070 \\
\hline & $(0.333)$ & $(0.423)$ & $(0.255)$ \\
\hline \multirow[t]{2}{*}{ Age 25-29 } & 0.162 & 0.210 & 0.135 \\
\hline & $(0.368)$ & $(0.407)$ & $(0.342)$ \\
\hline \multirow[t]{2}{*}{ Age 30-34 } & 0.144 & 0.136 & 0.149 \\
\hline & $(0.351)$ & $(0.343)$ & $(0.356)$ \\
\hline
\end{tabular}




\begin{tabular}{cccc} 
Age 35-39 & 0.133 & 0.107 & 0.147 \\
& $(0.339)$ & $(0.309)$ & $(0.354)$ \\
Age 40-44 & 0.122 & 0.088 & 0.141 \\
& $(0.327)$ & $(0.283)$ & $(0.348)$ \\
Age 45-49 & 0.105 & 0.064 & 0.128 \\
& $(0.307)$ & $(0.245)$ & $(0.334)$ \\
Age 50-54 & 0.086 & 0.046 & 0.108 \\
& $(0.280)$ & $(0.209)$ & $(0.310)$ \\
Age 55-59 & 0.059 & 0.028 & 0.076 \\
& $(0.235)$ & $(0.164)$ & $(0.264)$ \\
Age 60-64 & 0.027 & 0.011 & 0.036 \\
& $(0.162)$ & $(0.106)$ & $(0.185)$ \\
Observations & 1976702 & 697602 & 1279100 \\
\hline
\end{tabular}

Source: Spanish Labour Force Survey 1996-2008. Reported are means of variables with standard deviations in parentheses. 
Table A2. IV-FE Estimates of the Effect of Permanent Contracts on Absence, Private Sector Workers 1996-2008.

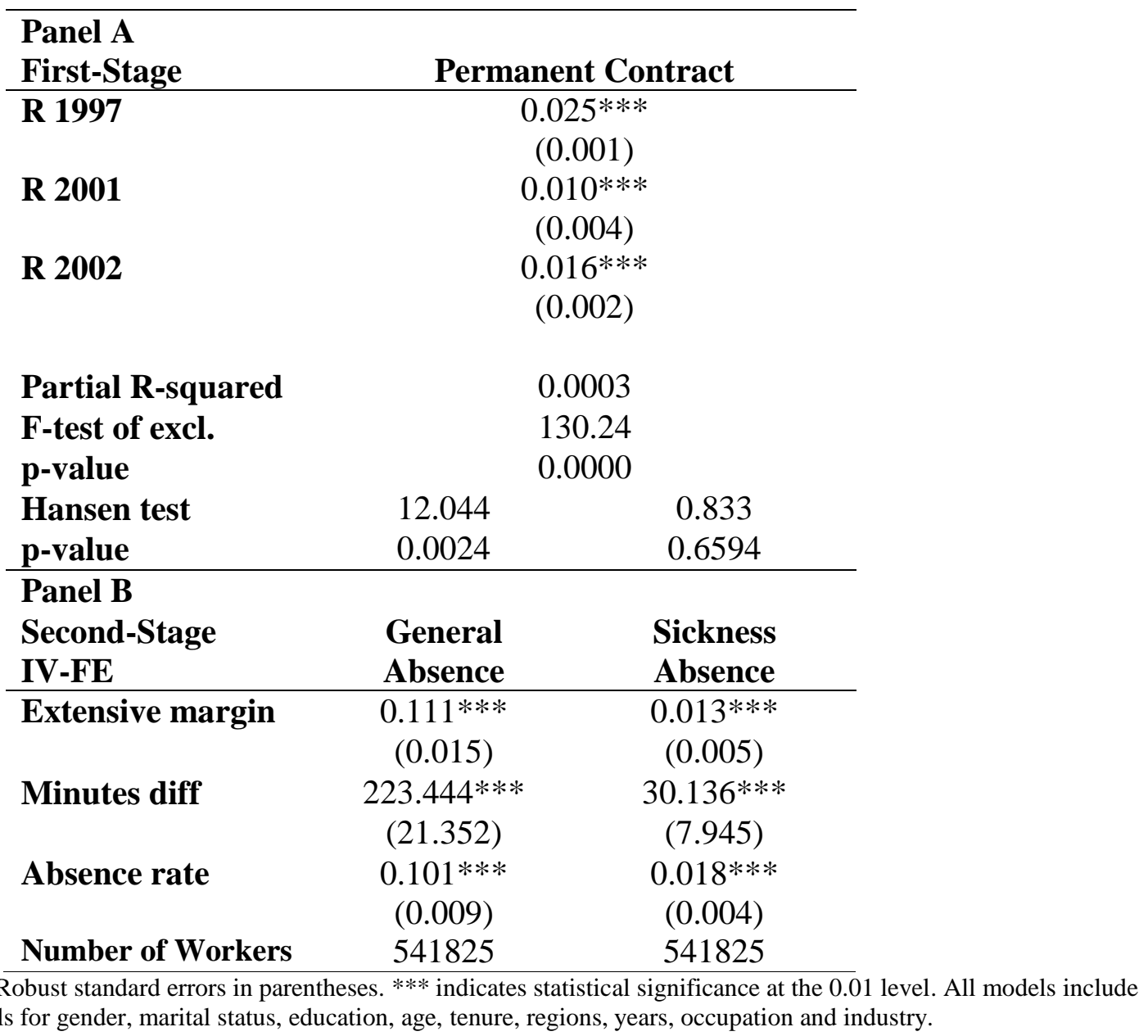


Table A3. IV-FE Estimates of the Effect of Permanent Contracts on Absence, Private Sector Workers 1996-2008. (Tenure <5yrs, Tenure <2yrs).

\begin{tabular}{|c|c|c|c|c|}
\hline $\begin{array}{l}\text { Panel A } \\
\text { First-Stage } \\
\end{array}$ & \multicolumn{2}{|c|}{ Tenure < 5yrs } & \multicolumn{2}{|c|}{ Tenure $<2$ yrs } \\
\hline R 1997 & \multicolumn{2}{|c|}{$0.025^{* * *}$} & \multicolumn{2}{|c|}{$0.023^{* * *} *$} \\
\hline & \multicolumn{2}{|c|}{$(0.002)$} & \multicolumn{2}{|c|}{$(0.002)$} \\
\hline R 2001 & \multicolumn{2}{|c|}{$0.010 * *$} & \multicolumn{2}{|c|}{$0.008 *$} \\
\hline & \multicolumn{2}{|c|}{$(0.004)$} & \multicolumn{2}{|c|}{$(0.005)$} \\
\hline R 2002 & \multicolumn{2}{|c|}{$0.027 * * *$} & \multicolumn{2}{|c|}{$0.048 * * *$} \\
\hline & \multicolumn{2}{|c|}{$(0.003)$} & \multicolumn{2}{|c|}{$(0.003)$} \\
\hline Partial R- & \multirow{2}{*}{\multicolumn{2}{|c|}{0.0004}} & \multirow{2}{*}{\multicolumn{2}{|c|}{0.0006}} \\
\hline squared & & & & \\
\hline F-test of excl. & \multirow{2}{*}{\multicolumn{2}{|c|}{$\begin{array}{l}113.82 \\
0.0000\end{array}$}} & \multicolumn{2}{|c|}{133.47} \\
\hline p-value & & & & \\
\hline Hansen test & 11.272 & 0.272 & 20.623 & 1.946 \\
\hline p-value & 0.0036 & 0.8729 & 0.0000 & 0.3779 \\
\hline \multicolumn{5}{|l|}{ Panel B } \\
\hline Second-Stage & General & Sickness & General & Sickness \\
\hline IV-FE & Absence & Absence & Absence & Absence \\
\hline Extensive margin & $\begin{array}{c}0.143 * * * \\
(0.017)\end{array}$ & $\begin{array}{c}0.029 * * * \\
(0.005)\end{array}$ & $\begin{array}{c}0.153 * * * \\
(0.025)\end{array}$ & $\begin{array}{c}0.030 * * * \\
(0.007)\end{array}$ \\
\hline Minutes diff & $\begin{array}{c}269.087 * * * \\
(23.491)\end{array}$ & $\begin{array}{c}54.862 * * * \\
(9.013)\end{array}$ & $\begin{array}{c}289.869 * * * \\
(32.829)\end{array}$ & $\begin{array}{c}47.600 * * * \\
(13.014)\end{array}$ \\
\hline Absence rate & $\begin{array}{c}0.125 * * * \\
(0.010)\end{array}$ & $\begin{array}{c}0.030 * * * \\
(0.004)\end{array}$ & $\begin{array}{c}0.139 * * * \\
(0.015)\end{array}$ & $\begin{array}{c}0.029 * * * \\
(0.006)\end{array}$ \\
\hline $\begin{array}{l}\text { Number of } \\
\text { Workers }\end{array}$ & 369272 & 369272 & 261958 & 261958 \\
\hline
\end{tabular}


Table A4. Plausible exogeneity bounds estimates, subsamples

\begin{tabular}{|c|c|c|c|c|c|}
\hline & \multicolumn{3}{|c|}{ Local to zero approximation } & \multicolumn{2}{|c|}{ UCI $(95 \%)$} \\
\hline & Coeff & \multicolumn{2}{|c|}{$\begin{array}{c}95 \% \text { Confidence } \\
\text { interval }\end{array}$} & $\begin{array}{l}\text { [Lower } \\
\text { bound }\end{array}$ & $\begin{array}{l}\text { Upper } \\
\text { bound] }\end{array}$ \\
\hline \multicolumn{6}{|l|}{$\begin{array}{l}\text { Private Sector }<5 y r s \\
\text { Tenure }\end{array}$} \\
\hline \multicolumn{6}{|l|}{ General Absence } \\
\hline Extensive margin & 0.062 & {$[0.001$} & $0.122]$ & -0.152 & 0.276 \\
\hline Minutes difference & 118.336 & {$[34.447$} & 202.226] & 61.073 & 175.601 \\
\hline Absence rate & 0.048 & {$[0.011$} & $0.085]$ & -0.149 & 0.246 \\
\hline \multicolumn{6}{|l|}{ Sickness Absence } \\
\hline Extensive margin & 0.026 & {$[0.006$} & $0.045]$ & -0.161 & 0.213 \\
\hline Minutes difference & 59.363 & {$[20.703$} & 98.024] & 32.491 & 86.238 \\
\hline Absence rate & 0.024 & {$[0.006$} & $0.041]$ & -0.159 & 0.207 \\
\hline \multicolumn{6}{|l|}{$\begin{array}{l}\text { Private Sector }<2 \mathrm{yrs} \\
\text { Tenure } \\
\text { General Absence }\end{array}$} \\
\hline Extensive margin & 0.066 & {$[0.011$} & $0.122]$ & -0.190 & 0.324 \\
\hline Minutes difference & 100.548 & {$[26.030$} & $175.065]$ & 47.027 & 154.070 \\
\hline Absence rate & 0.042 & {$[0.009$} & $0.074]$ & -0.201 & 0.285 \\
\hline \multicolumn{6}{|l|}{ Sickness Absence } \\
\hline Extensive margin & 0.019 & {$[0.004$} & $0.033]$ & -0.081 & 0.118 \\
\hline Minutes difference & 38.543 & {$[10.255$} & $66.832]$ & 20.378 & 56.709 \\
\hline Absence rate & 0.017 & {$[0.005$} & $0.030]$ & -0.079 & 0.114 \\
\hline
\end{tabular}

Note: All controls as per Table 1. 